\title{
Sumac (Rhus coriaria) Extracts to Enhance the Microbiological Safety of the Red Meat
}

\author{
Sami EI Khatib ${ }^{1,2, *}$, Abir Salame ${ }^{2}$ \\ ${ }^{1}$ Department of Biological Sciences, Lebanese International University, Lebanon \\ ${ }^{2}$ Department of Food Sciences, Lebanese International University, Lebanon
}

Received September 2, 2019; Revised October 25, 2019; Accepted November 4, 2019

Copyright $(2019$ by authors, all rights reserved. Authors agree that this article remains permanently open access under the terms of the Creative Commons Attribution License 4.0 International License

\begin{abstract}
Despite the great progress in reducing malnutrition and famine eradication in many countries, our planet's population continues to be affected by many food-related defies, including vitamin and mineral deficiencies, obesity, and non-communicable diseases. These challenges are fuelled, in part, by cheap, convenient, and highly-processed foods. However, food threats are not restricted to these mentioned issues. One area to which the international community has given substantial attention is ensuring the safety from infection and contamination of the food we produce, trade, and eat. It would be disastrous if our substantial foods were to become unsafe for consumption. More efforts need to be provided to prevent food insecurity starting from aligning policies in agriculture, trade, health, education, and social protection to provide a safe and healthy diet for all. Unfortunately, food safety in Lebanon is a neglected issue. Many Lebanese food products are labeled as "unsafe" in the local and international markets, and the burden of food safety has widely increased. As meat is considered perishable food and is of great concern especially in small Lebanese butcher shops, and the absence of an updated law that protects the consumer from contaminated meat, it was important to look for an alternative method to render meat safer for consumption. Rhus coriaria or commonly known as "Sumac" has shown a promising potent anti-bacterial and antioxidant effects, and therefore, it would be interesting to assess the potential use of this condiment as a food preservative and to evaluate the prospective introduction of such artisanal product to secure the meat safety and reduce its contamination.
\end{abstract}

Keywords Food Safety, Red Meat, Rhus coriaria, Sumac, Preservative, Antioxidant

\section{Introduction}

The industrial revolution has been defined in modern history as the series of changes from a traditional, handicraft, inefficient economy to one dominated by industry and technology. This progress has led to the advancement of different societies in all their aspects, including food and food industry. Agriculture and food industry prospered like never before, and food has been made available to a relatively larger number of people. However, this development was anticipated with greater challenges especially with the increase of foodborne risks as a result of the expansion and liberation of the international trade, climate changes, increased levels of pollution in the environment along with the increased corruption, in developing countries. According to statistics published by the Center of Disease Control and Prevention (CDC), 48 million Americans were at a risk of foodborne illness, contributing to 128000 hospitalizations and 3000 deaths from 1998 to 2008 (Painter, 2008). For this reason, the World Health Organization (WHO), a specialized agency of the United Nations, considered food safety one of its crucial priorities to promote the health of the global population, and started along with international administrations and organizations in making steps towards a safer food chain system. Locally, Lebanon has made little progress in developing an efficient food safety system, and as many sectors, unfortunately, food and food safety remained one of the neglected issues over years. This fact has led to the aggravation of the food safety in Lebanon; many Lebanese products were rejected in the international markets because they were lack minimal safety requirements, and the burden of foodborne illness dramatically increased as many food products found in the Lebanese market were labeled as "unsafe" as they contained deadly toxins and harmful pathogenic bacteria. In order to shed a light on this crisis we will be focusing doing the discuss in engaging effective strategies that could be followed to turn our food products harmless to be consumed, hoping that a more effective food safety system would be embraced in Lebanon soon. Because meat is considered a high-risk food, and represents one of the most 
important food groups consumed by the Lebanese population, it was crucial to focus on its safety. Updated demonstrations gave an increased interest on medicinal herbs to be used as natural preservatives in food, including meat. Rhus coriaria (Sumac) could be chosen as a natural preservative for meat because it is widely used as a seasoning herb all along the Mediterranean region. This review, will firstly, focus on the routes and process of meat contamination, the main sources of contaminant agents, and their impact on the health and quality of meat. We then shed the light on the traditional food safety measures that are currently applied to reduce the meat contamination screening their efficiency and validity. We also evaluate the situation of the food safety in Lebanon and the causes of this crisis. A retrospective screening of many studies provides an overview about the potential of Sumac extracts to reduce the growth of pathogenic bacteria, its effect on sensory and organoleptic properties of meat, and the safety level relative to the use of Sumac as a preservative.

\section{Contamination of Meat}

The quality of meat is determined upon many factors. These factors can be technical based or consumer based. The technical factors include: the nutrient value, colorants, additives, functional ingredients, their microbiological and general safety...etc. whereas the consumer-based quality determinants are the flavor, textures, color, outer appearance which are relatively nonobjective and differ from one person to another. Microorganisms are ubiquitous, even in food. Not all types of microbes are harmful, however over 25 different microorganisms in meat and meat products, could cause serious foodborne illness and dramatically affect the human health especially that meat is considered a perishable food (Nollet, 2007).

\subsection{Types of Possible Contamination Factors during Meat Handling}

According to the Australian Institute (AIFS) of Food Safety food contaminants could be divided into in three different types: chemical, physical and biological. These could occur at any level of meat handling and processing (AIFS, 2018).

\subsubsection{Chemical Contamination}

Chemical contamination is defined as being the presence of an unusual substance in food or the presence of a substance in a high concentration that could be toxic for human consumption. This type of contamination can contribute to foodborne illness as they can cause toxicity that ranges from slight poisoning to severe renal, hepatic and neurological syndromes leading to death (Rather, 2017). Contamination occurs when food service chemicals are introduced to food by accident (Rather, 2017). These chemicals are widely used in food plants and factories for the purposes of disinfection. It is possible that contamination also occurs at the level of environment and prior to the processing of food; such contamination can originate from polluted soil or water i.e. at the level of housing and feeding of animals in case of meat (Rather, 2017). Cross contamination could occur from utensils previously disinfected by chemicals, also from pest control chemicals (UNL, 2019). It is the responsibility of the food service manager and the quality controller to avoid chemical contamination by following clear guidelines and precautions that allow proper handling to such chemicals and to evaluate the raw material before processing, and recruiting professional pest control managers to prevent chemical cross contamination (Motarjemi, 2013). Furthermore, this chemical contamination can also occur during transportation of meat from the exhaust of the vehicles, the packaging material, or the chemicals that are added for preservation purposes when transportation occurs for a long period of time (Rather, 2017). Table 1 summarizes examples of chemical hazards that could occur in meat (UNL, 2019).

Table 1. Examples of chemical hazards in meat (UNL, 2019)

\begin{tabular}{|c|l|}
\hline Raw material & $\begin{array}{l}\text { Pesticides, antibiotics, hormones, } \\
\text { fertilizers, fungicides, heavy metals }\end{array}$ \\
\hline Processing & $\begin{array}{l}\text { Direct food additives/ preservatives } \\
\text { (nitrites), flavor enhancers, color } \\
\text { additives }\end{array}$ \\
\hline $\begin{array}{c}\text { Building and equipment } \\
\text { maintenance }\end{array}$ & Lubricants, paints, coating \\
\hline Sanitation & Pesticides, cleaners, sanitizers \\
\hline Storage and shipping & $\begin{array}{l}\text { All types of chemicals and cross } \\
\text { contaminations }\end{array}$ \\
\hline
\end{tabular}

\subsubsection{Physical Contamination}

Physical contaminations can also occur accidently during food handling. It is the introduction of foreign bodies into food that are most of the time visible contaminants like hair, nails, jewelry, metal pieces from equipment...etc. This kind of contamination is usually avoided by applying good hygienic practices of the serving personnel (Motarjemi, 2013).

\subsubsection{Bacterial Contamination}

According to a study conducted by the Center for Disease Control and Prevention CDC, foodborne illness victims reach million cases in America with a total of 3000 deaths (Painter, 2013). In Lebanon, according to the Ministry of Public Health, intestinal infectious diseases accounted for 2166 cases out of 93672 registered during 11 months in a study piloted in 2004 (El Zain, 2002). Noting that the Ministry covers about $48 \%$ of the Lebanese population so the number might be doubled. Infectious intestinal diseases also affected infants dramatically (El Zain, 2004).

Since food makes a great source of nutrients, protein, fat and water, it is considered to be an ideal environment for microbial growth and proliferation, namely bacteria and 
fungi. Microorganisms are wide spread around us so food can be contaminated when they are in contact with soil, water, air, during processing and preparation (Marriot, 1997). Meat is considered as a high-risk food and its poor inappropriate handling can lead to bacterial contamination and hence severe foodborne illnesses. The most commonly found pathogenic bacteria in meat are namely Salmonella, Staphylococci, Clostridium botulinum, Campylo Bacter, and Escherichia. coli. Bacterial contamination of meat is considered hazardous because it is one of the major contributors to foodborne illnesses both infectious and intoxication types. Each and every one of the mentioned bacteria have favorable growth conditions of temperature, water activity, oxygen levels and $\mathrm{pH}$ in which each follows a specific growth pattern (Marriot, 1997).

To evaluate the safety and quality of meat, three types of microorganisms must be identified: mesophilic aerobes (MA), total coliforms (TC) and E. coli. Increased levels of MA indicate low quality meat with a reduced shelf life, whereas high levels of TC and the presence of E. coli indicate poor hygienic practices during meat handling, in addition to the presence of fecal contamination (Barrous, 2007). Mold counts verify the sanitary quality of the plant including the cleanliness of the equipment and machines used during processing (Barrous, 2007). According to the USDA, E. coli identification through tests is mandatory in both meat and poultry (Barrous, 2007). Bacterial contamination is not eliminated when the carcasses are washed with water, and in some cases, it led to more contamination in which the TC and MA levels are significantly increased (Jaja, 2018).

Table 2. The acceptable and unacceptable microbiological counts in fresh meat (Food and Agriculture Organization of the United Nations FAO, 2016)

\begin{tabular}{|c|c|c|c|}
\hline & $\begin{array}{c}\text { Good } \\
\text { microbiological } \\
\text { standard }\end{array}$ & $\begin{array}{c}\text { Critical } \\
\text { microbiological } \\
\text { condition }\end{array}$ & $\begin{array}{c}\text { Not } \\
\text { acceptable }\end{array}$ \\
\hline $\begin{array}{c}\text { Total plate } \\
\text { count per } \mathrm{cm}^{2}\end{array}$ & Less than $10^{4}$ & $\begin{array}{c}\text { Between } 10^{4} \\
\text { and } 10^{5}\end{array}$ & $\begin{array}{c}\text { More than } \\
10^{5}\end{array}$ \\
\hline
\end{tabular}

\subsection{Sources of Bacterial Contamination}

The major causes of contamination include lack of hygienic requirements, inferior food manufacturing practices, lack of technical and scientific education related to cross-contamination, and most importantly absence of official strategic control. Meat can be contaminated at three different levels during its handling: in the slaughters, when in process, and during storage and transportation (UNIDO, 2009).

\subsubsection{At the Level of Slaughters}

Animal carcasses are the major source of bacteria during slaughter. Although animal muscles are considered sterile as they are protected by the animal's immune system when still alive, they can be contaminated from normal flora and pathogenic bacteria found on the animal's skin that is in direct contact with the external environment. Pre slaughter conditions such as feeding and housing of the animal must be first evaluated before the animal is slaughtered and the meat is processed because there is a high risk that the animal had fed on contaminated water and food, or gotten fecal contamination. The initial process of evisceration might also contaminate carcasses and equipment (Bakhtiary, 2016). Placing the animal on the floor for slaughtering can also be a source of contamination for bacteria especially that the temperature of the floor is optimum for bacterial multiplication (Lahr, 1996). Adding to this, contamination can occur when contaminated knives are used for the slaughtering process where the blood carries the microbes throughout the whole carcass. Animal hangers are a source of contamination when used several times without its proper sanitation i.e. cross contamination (Marriot, 1997).

\subsubsection{At the Level of Production}

Processing of meat relies on good manufacturing and hygienic practices to reduce the microbial load to an acceptable level. In a study conducted to evaluate meat hygiene in Brasil, meat can be highly contaminated during its preparation and processing (Barrous, 2007). For the sake of the study many meat samples were collected from different processing points and evaluated microbiologically. The results indicated that contamination of meat occurred mainly in plastic boxes, beef tenderizers, sausage stuffers, mixers and grinders, which are difficult to clean and can accumulate large amounts of organic matter, favoring microbial growth and reducing the efficacy of sanitization procedures. Stainless steel utensils also showed high levels of contamination especially that sanitization and cleaning processes were not carried out on daily basis. The knives used for filleting and cutting were not sanitized at any of the ten meat retail establishments visited in Brazil in the aim of evaluation of safety of meat (Barrous, 2007). The improper use of utensils for meat cutting can also cause cross contamination. Exploiting wooden cutting boards can accumulate bacteria inside the dents and holes created in it which causes in turn cross contamination (Motarjemi, 2013). Using the same cutting board for chicken meat and fish is also a source of cross contamination (Motarjemi, 2013). Moreover, it was also noticed that improper personnel hygiene can cause microbial contamination. For example, handling meat after toilet use without proper cleaning and sanitization of hands can cause severe bacterial contamination namely fecal contamination which leads to severe foodborne illness (Motarjemi, 2013).

\subsubsection{At the Level of Storage and Transportation}

The most critical factor to take into consideration in the storage of meat is the temperature since bacteria proliferates quickly at higher temperatures. The most ambient temperature to store meat is at 2 to 5 degrees, and for freezing it is -18 degrees Celsius (Motarjemi, 2013). It 
is proven that inappropriate storage temperatures also affect the color stability. The most important factor for maintaining the red oxymyoglobin color and keeping lipid oxidation to a minimum is the storage temperature. Therefore, different cooling rates affect oxidation or oxygenation of meat and thus change the color of the meat surface, an additional effect to bacterial proliferation in meat (Rani, 2015). It is important to place meat at the bottom of the fridge to prevent cross contamination from meat to other types of food (Motarjemi, 2013). In addition to proper storage conditions, suitable packaging must be also considered as an important factor to prevent bacterial contamination (Rani, 2015). Understanding the packaging options and their effects on meat is important, since they have an effect on its quality. Vacuum packaging is used to prevent the growth of aerobic spoilage organisms, shrinkage, oxidation, and color deterioration. Temperature and the microbiological status of the meat at the time of packing are also a significant factor for the safety of meat (Rani, 2015).

Transportation of meat plays a critical role in meat contamination especially if meat is being transported at unsuitable conditions. Carcasses must be chilled to 4 degrees before transporting it to reduce pathogenic microbial growth and when transporting meat, the challenge is to maintain proper refrigeration temperatures and keep the cold chain from breaking during steps such as palletization, staging, loading and unloading of containers, and in storage (Carr, 2017). To guarantee a healthy fresh product, the time of transportation from producer to consumer must be as short as possible, must not be handled by personnel during transport, and the meat and meat products should be packaged and checked for leakers, temperature, packaging etc. before transportation (Carr, 2017).

\subsection{The Impact of Meat Contamination}

Contamination could affect both the safety and the quality of the consumed meat. Meat is considered a high-risk food because as it makes a good survival environment for bacteria and thus leads to foodborne illness when consumed (Motarjemi, 2013). The quality of meat is also affected as a result of bacterial contamination. This is due to several spoilage compounds produced by different types of bacteria like Ammonia for example from aerobic spoilers (Gracia, 1998).

\subsubsection{The Impact of Meat Contamination on Human Health: Foodborne Illness}

According to the National Institute of Diabetes and Digestive and Kidney Diseases (NIDDK) foodborne illness is defined as:" Foodborne illnesses are infections or irritations of the gastrointestinal (GI) tract caused by food or beverages that contain harmful bacteria, parasites, viruses, or chemicals" (NIDDK, 2014). Foodborne illness mostly occurs when ingesting contaminated food with bacteria in particular which causes the infestation of various symptoms ranging from mild to severe; these symptoms include: nausea, vomiting, diarrhea, fever, abdominal pain...etc (WHO, 2019). Food poisoning from food contaminated with Clostridium botulinum may cause severe neurological damage and if severe enough may lead to death (WHO, 2019). Infection with E. coli may lead to hemolytic uremic syndrome (WHO, 2019). This syndrome damages the lining of the tiny blood vessels in the kidneys, sometimes leading to kidney failure. When it comes to Listeria monocytogenes infection, it may have severe effects especially to a pregnant woman in which it may cause miscarriage or even a potentially still birth. Some high-risk groups such as children, pregnant women, older adults and those who suffer from chronic diseases such as AIDS are at a higher risk of developing food poisoning (WHO, 2019).

\subsubsection{The Impact of Bacterial Contamination on the Quality of Meat}

Bacterial contamination of meat is a cause of tremendous financial losses in giant industries, because this kind of contamination does not only make the consumer ill, but also it causes unpleasant sensorial changes so that meat is not accepted at the level of the market. These changes include rancidity, fermentation, putrefaction, souring, turbidity, slime formation and mold growth. Each manifestation is caused by a different type of bacteria (FAO, 2016).

Table 3. The sensorial changes caused by spoilage by different types of bacteria $(\mathrm{FAO}, 2016)$

\begin{tabular}{|c|c|}
\hline Putrefaction & Pseudomonas, Proteus, Clostridium \\
\hline Souring & Lactobacillus, Enterococcus, Pediococcus \\
\hline Fermentation & Yeasts (Saccharocyces), Enterobacteriaceae \\
\hline Turbidity & Lactic Acid Bacteria, Enterobacteriaceae \\
\hline $\begin{array}{c}\text { Greenish } \\
\text { discoloration }\end{array}$ & Lactic Acid Bacteria \\
\hline $\begin{array}{c}\text { Slime } \\
\text { formation }\end{array}$ & Pseudomonas, Streptococcus, \\
\hline Mold growth & Penicillium, Aspergillus, Mucor, Yeasts \\
\hline
\end{tabular}

\section{Food Safety Measures: Types and Efficiency}

One of the major roles of the World Health Organization (WHO) is to promote health at the level of the world and considers the safety of food one of the major contributors to human's health. This represents a good reason to promote food safety programs along with health organizations to maintain safety of food to be consumed and decrease the burden of foodborne illnesses (WHO, 2002). 


\subsection{Usual Practiced Food Safety Measures to Reduce Contamination}

Ever since the human kind existed, food availability was always a priority. As time passed, humans were more concerned on the preparation and preservation of their food. Food preservation started with primitive measures such as salting and using herbs, and as technology raided the world, more sophisticated methods appeared such as freezing and canning. Many studies demonstrated that microbes could be a direct cause to food spoilage especially after the milk borne illnesses outbreaks that appeared in the early 1920s in America which necessitated the monitoring of times and temperatures of milk collection, proper cleaning of the equipment, pasteurization of milk...etc. The need of space astronauts in NASA for safe food during their long trips and the unavailability of freezers into spaceships at that time created a severe need for a method that monitors the safety of food at many levels. The idea of establishing safer food prospered to be applied at the level of many food service institutions like restaurants, hospitals, nursing homes, and others as they were developed by Micheal Pillusbury, a fellow for National Science Foundation in Taiwan, along with the Food and Drug Administration as Hazard Analysis and Critical Control Point system and Good Hygiene practices to control food hazards (Surak, 2002) .

\subsubsection{Hazard Analysis and Critical Control Points HACCP}

The HACCP plan is a system that allows the identification of hazards that put food processed at risk. According to the FDA, HACCP can be defined as a system that includes seven points: analyzing hazards, identifying critical control points, establishing preventive methods, establishing a procedure to monitor critical control points, establishing corrective actions, establishing a procedure to verify that the system is on track, and finally establishing a good record (Surak, 2002). Hazard analysis includes the identification of potential hazards (biological, physical, or chemical) and taking a measure to control this hazard. A critical control point is a point in a food processing chain in which a potential hazard may occur, these points are identified so that they can be eliminated. Taking preventive measures to control a food hazard is establishing a critical limit that should not be exceeded to render food safe and monitoring it. For example, establishing a minimum cooking temperature when cooking meat or poultry and checking the temperature at the different processing points. If this limit is exceeded, a corrective action should be pre-established to be applied directly; for example, disposing food if the proper temperature is not met during cooking. To make sure that the system has been placed-on track, one must monitor the temperature and time devices so that the values collected are right and the cooking unit is well controlled (Surak, 2002). The main goal of embracing a HACCP system in meat processing is to reduce, prevent and/or eliminate microbial contamination that occurs mainly during meat handling and these goals are crucial in meat processing to produce meat with added value in terms of quality and safety (FAO, 2016).

\subsubsection{Good Hygiene Practice (GHP)}

Good hygienic practices are basic sanitary rules that are specific to each food service institution. They also include laws and regulations issued by international food safety organizations to produce safe food. In meat production GHP include sanitary actions that should be applied to meat and meat products, equipment used and personnel. GHP for meat processing plants start with the compliance of the layout and design of the plant and the equipment in terms of function and sanitation with the international standards. Secondly, food servers must purchase safe raw material that meet great sanitation and quality standards to obtain a safe end product. Food servers must conduct adequate processing methods of meat so that they are not contaminated during processing. Adding to this, proper pest control and cleaning procedures should be highlighted as obligatory as they are basic procedures to control contamination during food processing. Monitoring the quality and cleanliness of water used is also necessary, because polluted water can cause contamination at every point of processing. Last but not least, food service managers should conduct hygiene training sessions in which the staff learns basic sanitary applications as well as monitoring of their health (FAO, 2016).

\section{Food Safety in Lebanon: Current Situation, Compliance to Standards, Impacts \& Importance}

One of the major contributors to the health of a population and economy is food safety. Food safety has always been a concern in Lebanon, in particular after the campaign conducted by the Ministry of Public Health (MOPH) launched in November 2014 and proved the presence of bacterial contaminants like Salmonella and E. coli as a result of the poor basic hygienic practices in restaurants and food service institutions all around Lebanon. The latter led to numerous food poisoning outbreaks and rejection of various exported Lebanese products (Jardali, 2014).

\subsection{Current Situation and Compliance of the Lebanese Meat Industry Sector with Food Safety Regulations}

The campaign conducted by the Ministry of Public Health led to the closure of more than 1000 restaurants and slaughter houses (WHO, 2015). In fact, the Lebanese butcher shops showed a low awareness level about implementing food safety regulations in meat and meat 
products. Carcasses were exposed to open air outside the shops, especially butchers located in crowded areas, making the carcasses susceptible to high levels of the three types of contaminations: microbial, chemical and physical contaminations. Adding to this, the improper building design makes meat at a high risk of contamination during slaughtering as they lack compliance with international standards. Internal walls, windows, doors, floors, drains and most of other infrastructures are in most of cases out of specifications, for example most of the inspected institutions had iron doors which are highly susceptible to rusting due to humidity, drains are not sanitary and most of the inspected sites they are used for both sewage and industrial waste, a situation that is objectionable in food industry. It is concluded that the Lebanese meat manufacturing sector is traditional and is highly exposed to contamination (UNIDO, 2009). Despite the devastating situation of the food safety, no changes in the food safety practices were made in Lebanon. The Lebanese government, unfortunately, did not succeed in issuing an updated law that obligates food service institutions to comply with, instead, the Lebanese food industry remained a victim of ancient decrees that are totally outdated. This fact has led to the rejection of the Lebanese products in international markets because of total absence in the compliance with international standards. Locally, thousands of food-borne illness cases, in which $95 \%$ were a cause of consuming bacteria contaminated food (UNIDO, 2009), were reported by the Ministry of Public Health as a result to the presence of Salmonella, E. Coli, Staphylococcus Aureus, and Listeria Monocytogenes in samples collected from different restaurants. The presence of nine different food safety organizations has partially failed to promote effective plans to establish a food safety system due to lack of cooperation, lack of efficiency, the absence of a good food law, and the inability to control microbial and chemical contaminations and the excessive use of additives in food industries. Thirteen years of passive trials passed, but no improvement in the food safety system has occurred (Jardali, 2014).

\subsection{Justification of the Food Safety Crisis in Lebanon}

In a trial to understand the food safety system in Lebanon and enhancing it, a food safety Panel was created. This Panel's role was to collect information from almost all stakeholders involved in food industry and evaluate their compliance with food safety regulations. After inspection, the following findings were conducted (UNIDO, 2009).

Many food service institutions and industries do not comply with food safety regulations, food safety laws and decrees are outdated and even if fulfilled are not effective in enhancing the safety of food, lack of proper planning and communication between ministerial parties has led to ineffective measures and overlapping duties, as well as a successful inspection and monitoring system is almost totally absent (UNIDO, 2002). This can be explained by many reasons that form a barrier to enhance the food safety system in Lebanon. One of the causes of this corruption is due to the huge political, economic and environmental instabilities. This has led to shadowing of many foodborne illness cases and surveillance of the non-complying food service systems with food safety regulations, the lack of scientific and technical expertise and a major deficiency in laboratories, auditors and staff. Another cause could be referred to the lack of education and knowledge of staff and food handlers especially in the small businesses (Jardali, 2014).

\section{Using Sumac Extracts to Reduce Foodborne Pathogens in Red Meat}

Raw meat is considered an ideal medium for the survivor and growth of microbiological pathogens that if consumed may lead to foodborne illness. Meat is considered a perishable food, and can be easily contaminated if handled incorrectly that is why it has always been crucial to figure out sustainable preservation methods for meat. These include refrigeration, radiation, vacuum packaging, heat processing and the use of synthetic preservatives (Khalkhali, 2018). The presence of a food safety issue in Lebanon especially in the meat sector industry, as proven by the study conducted by the United Nations Industrial Development Organization in 2009 (UNIDO, 2009), the problem of land pollution and the biodegradability of plastic bags, the antibiotic resistance crisis that is threatening the world, and the risks associated with the use of synthetic preservatives, it was vital to find alternative methods for preservation that are more effective and efficient (Khalkhali, 2018). As a result of the current problems research and studies directed the use of medicinal plants to reduce pathogenic microorganisms in food to increase the shelf life of the products and render them safer for consumption. A promising herb that is showing amazing antimicrobial and antioxidant effect is the Rhus coriaria L. commonly known as Sumac (Khalkhali, 2018).

\subsection{Rhus coiraria (Sumac) Physiochemical Properties and Subsequent Benefits}

Rhus coiraria, commonly named as Sumac belongs to the Anacardiaceae family. It is originally a fruit that grows along the Mediterranean region and used as a powdered spice. It is known for its sour taste and used for seasoning in many known Mediterranean dishes and cuisine (Abu Reidah, 2014). Rhus coraria has been considered as a medicinal herb as it was used in ancient medicine as an antiseptic, analgesic, anti-inflammatory, anti-gastric, anti-ulcer, hepatoprotective and as an antibacterial agent (Gabr, 2014). Recently, it has been shown that Sumac offers also a tenderizing effect on red meat with a 
significant effect on collagen content (Sakhr \& El Khatib, 2019).

In the aim of studying and understanding the chemical composition of Sumac, several extracts were taken from different parts of the plant mentioning the fruits and the leaves. Aqueous, alcoholic and lipid extracts were prepared, and the chemical composition was evaluated via HPLC-MS (Ardalani, 2016). The results have revealed 191 different components of Rhus coriaria extracts shown as follows:

- 78 hydrolysable tannins

- 59 flavonoids

- 9 anthocyanins

- 2 isoflavonoids

- 2 terpenoids

- 1 diterpene

- $\quad 38$ other unidentified compounds (Ardalani, 2016)

Hydrolysable tannins were identified having the highest percentage in Sumac extracts, followed by flavonoids and anthocyanins, isoflavonoids, terpenoids, and diterpene in lower percentages. This explains the antioxidant potential of Rhus coriaria extracts (Ardalni, 2016). In a study conducted by El Jaber (2004) it was proven that gallic acid was also an identified component in Sumac extracts.

\subsubsection{The Potential of Rhus coriaria in Fighting Illnesses and Diseases}

Chakraborty et al. (2009) suggested that Rhus coriaria possess a proven anti-mutagenic and thus an anti-cancer property. This could be explained by the gallic acid content of Sumac extracts (Liu, 2011). Recent studies conducted on rats demonstrated that Rhus coraria proposed an anti-hyperglycemic effect as well as the ability to lower high lipoprotein levels that are associated with diabetes thus reducing the risk of coronary heart disease in diabetic patients (Shidfar, 2014). This effect is due to the scavenging effect of the phenolic compounds that provide Rhus coraria its antioxidant property and thus the ability to reduce the risk of chronic diseases besides its anti-microbial effect (Abu Riedah, 2014). Sumac extracts also play a role in enhancing dental hygiene and health by inhibiting the formation of dental plaques caused by several number of bacteria naming Streptococcus mutans for example (Dastjerdi, 2015). Moreover, Rhus coriaria extracts have been shown to have an effects against human bacterial infections. For the purpose of studying the antibacterial effect of Sumac, 1 alcoholic extract and another aqueous extract of Rhus coriaria were prepared, and 2 strains of Escherichia coli and another 2 strains of Pseudomonas aeruginosa were obtained from human epithelial cells. After the treatment of the bacteria with the two extracts in addition to Tetracycline, the adhesion zones of the bacteria were evaluated. The alcoholic (ethanol) extract was shown to be more effective than the hot water extract (tables $4 \& 5$ ) and as the concentration of the extract increased from $5 \mathrm{mg} / \mathrm{ml}$ to $40 \mathrm{mg} / \mathrm{ml}$ the higher the antimicrobial effect (Alwan, 2009).

Table 4. Effect of Rhus coriaria hot water extract on UTI bacteria (Alwan, 2009)

\begin{tabular}{|c|c|c|}
\hline \multicolumn{3}{|c|}{ Concentrations and control average adhesion diameter $(\mathrm{mm})$} \\
\hline $\mathrm{mg} / \mathrm{ml}$ & Isolated $P$. aeruginosa & Isolated $E$. coli \\
\hline 40 & 14 & 17 \\
\hline 20 & 8.5 & 10.2 \\
\hline 10 & 0 & 0 \\
\hline 5 & 0 & 0 \\
\hline Tetracycline & 3.8 & 6 \\
\hline Distilled water & 0 & 0 \\
\hline
\end{tabular}

Table 5. Effect of Rhus coriaria hot ethanol extract on UTI bacteria (Alwan, 2009)

\begin{tabular}{|c|c|c|}
\hline \multicolumn{3}{|c|}{ Concentrations and control average adhesion diameter $(\mathrm{mm})$} \\
\hline $\mathrm{mg} / \mathrm{ml}$ & Isolated $P$. aeruginosa & Isolated $E$. coli \\
\hline 40 & 18.5 & 20 \\
\hline 20 & 11.1 & 13.5 \\
\hline 10 & 0 & 5 \\
\hline 5 & 0 & 0 \\
\hline Tetracycline & 3.9 & 6.3 \\
\hline Distilled water & 0 & 0 \\
\hline
\end{tabular}

5.1.2. The Use of Rhus coriaria at the Level of Food Industry as a Natural Preservative

Due to the antioxidant and antimicrobial potential of Sumac extracts, an increased interest has been raised for the use of Rhus coriaria in food industry as a natural preservative as it is proven to be an effective inhibitor of the foodborne pathogens and thus increasing the shelf life of the products (Abu Reidah, 2014). In the aim of studying the antimicrobial effect of Sumac, a comparative study was conducted to evaluate the effect of Rhus coriaria extracts to that of lactic acid (Gulmez, 2006). 3 broiler wings groups were treated with distilled water, lactic acid, and sumac extracts. The results have shown that in all experiments, lactic acid had a greater potential in inhibiting psychrotrophs, mesophilic aerobes, enterobacteriaceae, coliforms, and presumptive fecal coliforms compared to both sumac-treated and distilled water treated wings (Gulmez, 2006) (Figure 1). However, because Sumac has shown a greater effectivity in reducing pathogens compared to distilled water, Sumac should be considered as a promising natural yet cheap preservative to be used at the level of food industry (Gulmez, 2006). 


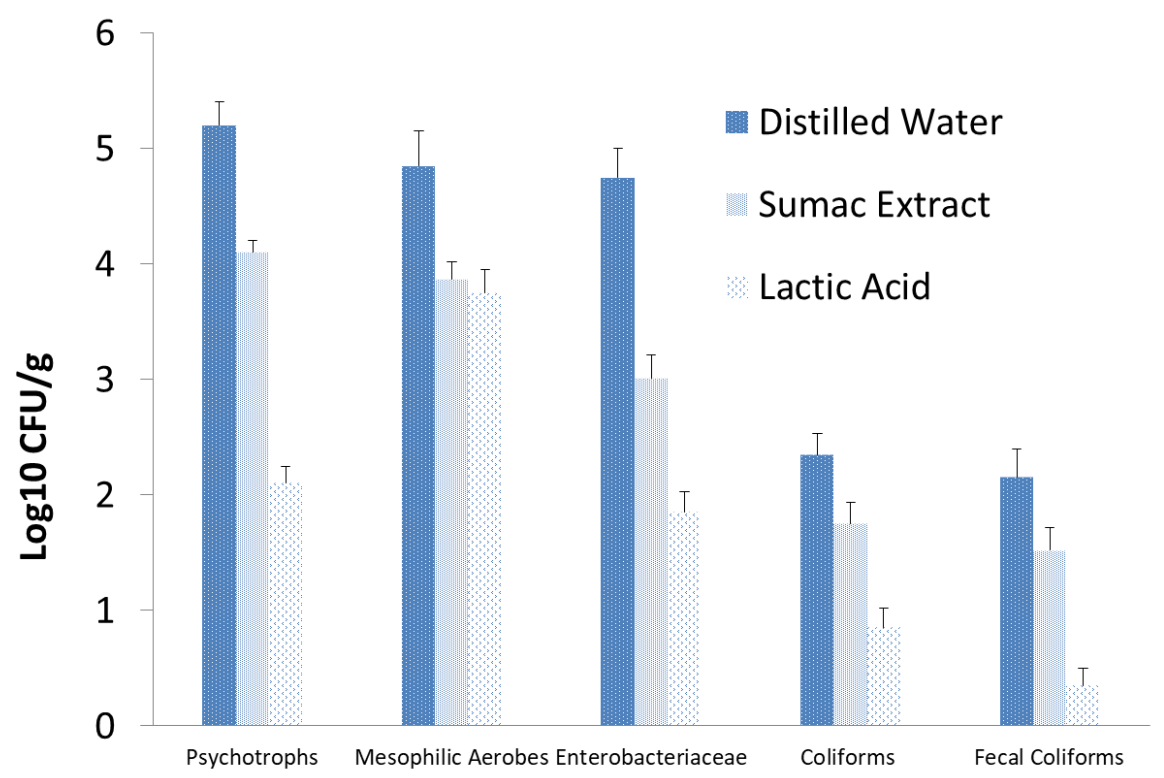

Figure 1. The colony counts of total contaminants after a $10 \mathrm{~min}$ decontamination using distilled water, sumac extract and lactic acid (Gulmez, 2006)

Another study was conducted to evaluate the antibacterial power of Sumac in poultry in which it was proven that Sumac is effective in inhibiting Salmonella typhimurium and Bacillus cereus for 7 days noting that it had a greater potential on Salmonella than Bacillus (Abdelmalek, 2013). Moreover, Sumac has shown an effect against Erwinia carotovora the causative agent of the soft rot disease in potato tuber (Obais, 2013). The study conducted has proven that the higher the concentration of the extract the greater is the effect (Obais, 2013) (Figures $2 \& 3$ ).

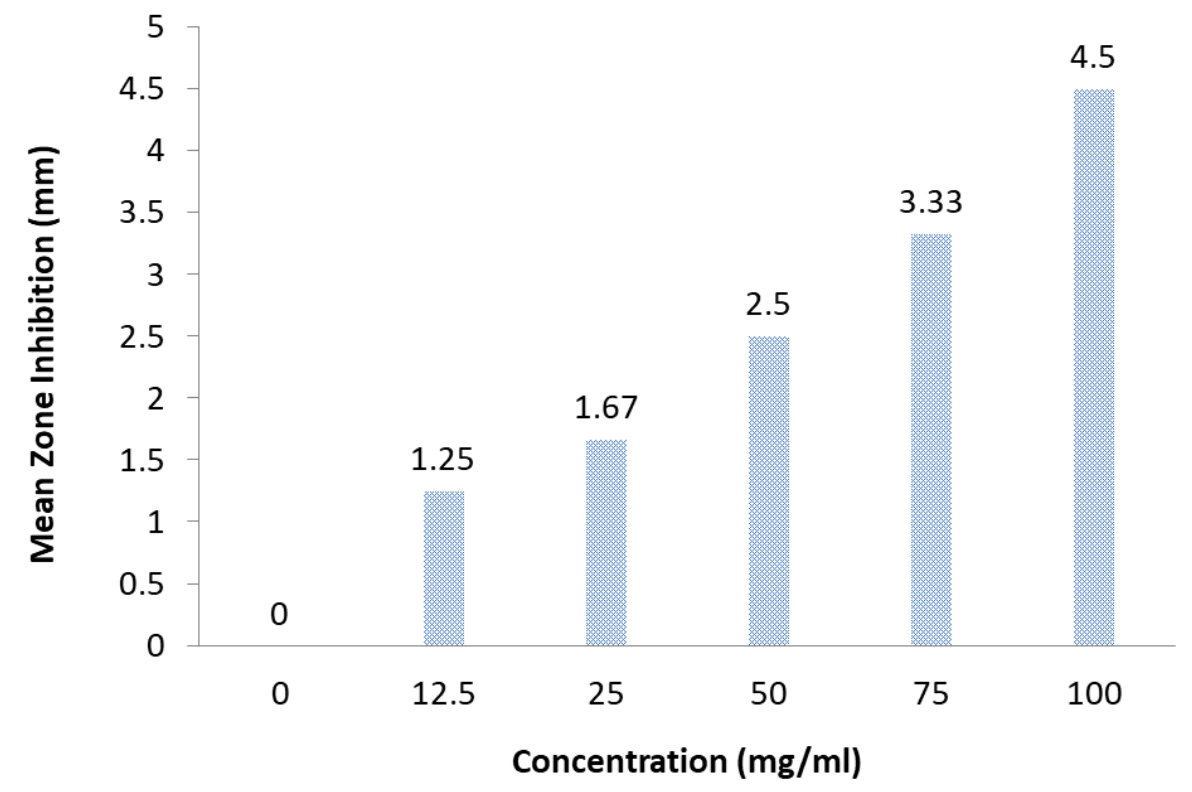

Figure 2. Effect of different concentrations of ethanolic extracts of Rhus coriaria on Erwinia carotovora bacterial growth (Obais, 2013) 


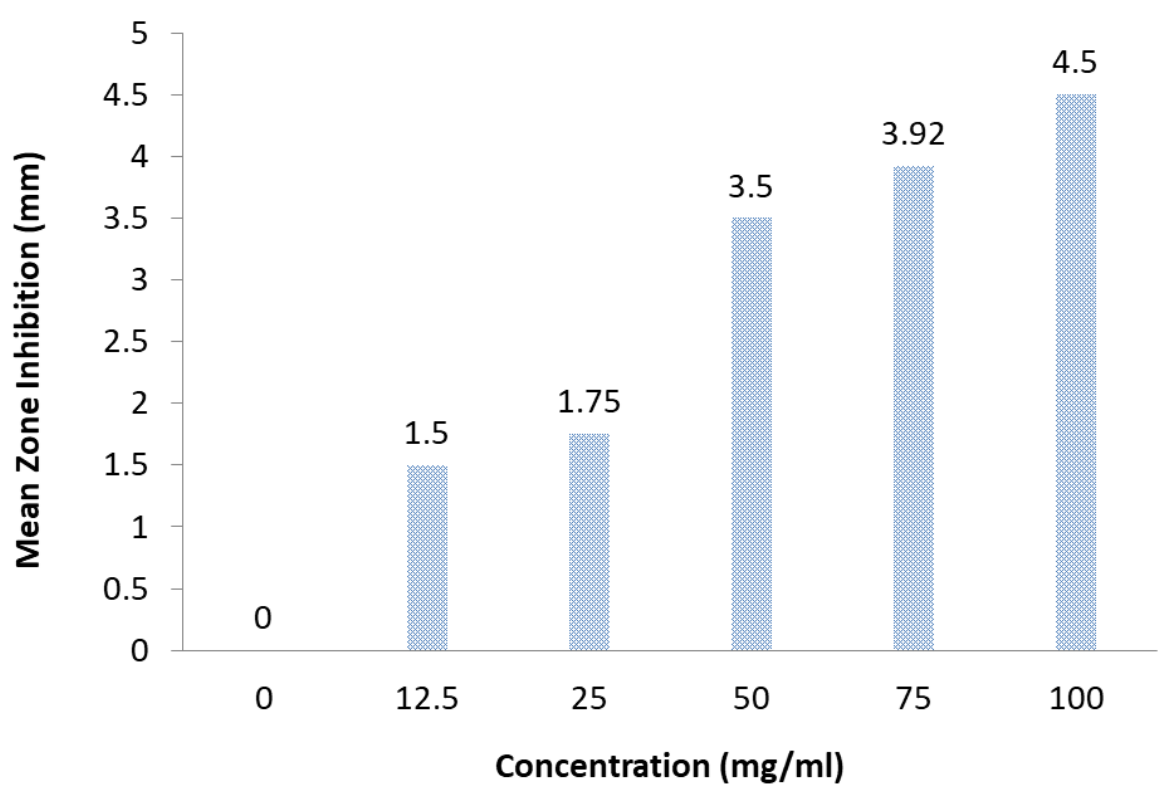

Figure 3. Effect of different concentrations of water extracts of Rhus coriaria on Erwinia carotovora bacterial growth (Obais, 2013)

5.2. The Effect of Rhus coriaria Extracts on the Pathogenic Microorganisms in Red Meat

Because of the lower cost, increased efficiency of natural plant extracts and relatively low side effects there is an increased interest of using medicinal plants as natural preservatives in food processing (Gabr, 2014).

In the aim of studying the anti-bacterial effect of Sumac, methanol, acetone and water extracts can be prepared from the fruits of Rhus coraria. Only methanol extract has shown an anti-bacterial effect (Gabr, 2014). In another study, the methanol extract of mature fruits of Rhus coraria have shown an inhibitory effect on 10 different types of Gram positive and Gram negative pathogenic bacteria including Staphylococcus aureus, Escherichia coli, Bacillus cereus, Yersinia enterocolita, Shigella dysentariae, and Salmonella enteriditis as the minimum inhibitory concentration (MIC) increased from 0.1 to 20 $\mathrm{mg} / \mathrm{ml}$ (Abu Reidah, 2014). This antibacterial effect can be referred to the 120 volatile active constituents of six different species of Rhus coraria that showed a greater potential than antibiotics in reducing microbial counts. These include terpene hydrocarbons, oxygenated terpenes, as well as famesyl acetone, hexahydrofamesyl acetone, aliphatic aldehydes, and most importantly Tannins (Gabr, 2014). Tannins are considered to have the most potent anti-bacterial effect that may exceed that of antibiotics
(Gabr, 2014) and that of synthetic preservatives like butylated hydroxytoluene (BHT), and butylated hydroxyanisole (BHA) (Gottardi, 2016). This toxicity is explained by the mechanism of action carried out on bacteria in which Tannins play a role in inhibiting extracellular enzymes, inhibition of oxidative phosphorylation which results in disruption of bacterial membrane, and the nutrient deprivation of substrates (Gabr, 2014). In a study established by Khalkhali and his colleagues (2018), three samples were prepared: the control sample, meat with $100 \mathrm{mg} / \mathrm{ml}$ Sumac water extract and meat with 200 and $400 \mathrm{mg} / \mathrm{ml} \mathrm{Sumac}$ water extracts. The results have shown that the total viable count (TVC) for bacteria reached $7 \log \mathrm{cfu} / \mathrm{g}$ on day 7 in the control sample, $7 \log$ cfu/g on day 6 in sample containing 100 $\mathrm{mg} / \mathrm{ml}$ of Sumac water extracts and $7 \mathrm{log} \mathrm{cfu} / \mathrm{g}$ in samples containing 200 and $400 \mathrm{mg} / \mathrm{ml}$ as shown in Figure 4, noting that the acceptable microbiological limit for meat is $7 \log$ cfu/g according to the International Commission on Microbiological Specifications for Foods (ICMFS) (Khalkhali, 2018). This led to the conclusion that Sumac extracts can reduce the microbial growth in ground beef meat during refrigerated storage, noting that the anti-microbial activity of Sumac can be enhanced if it is coupled with other herbal extracts like Rosemary (Khalkhali, 2018). 


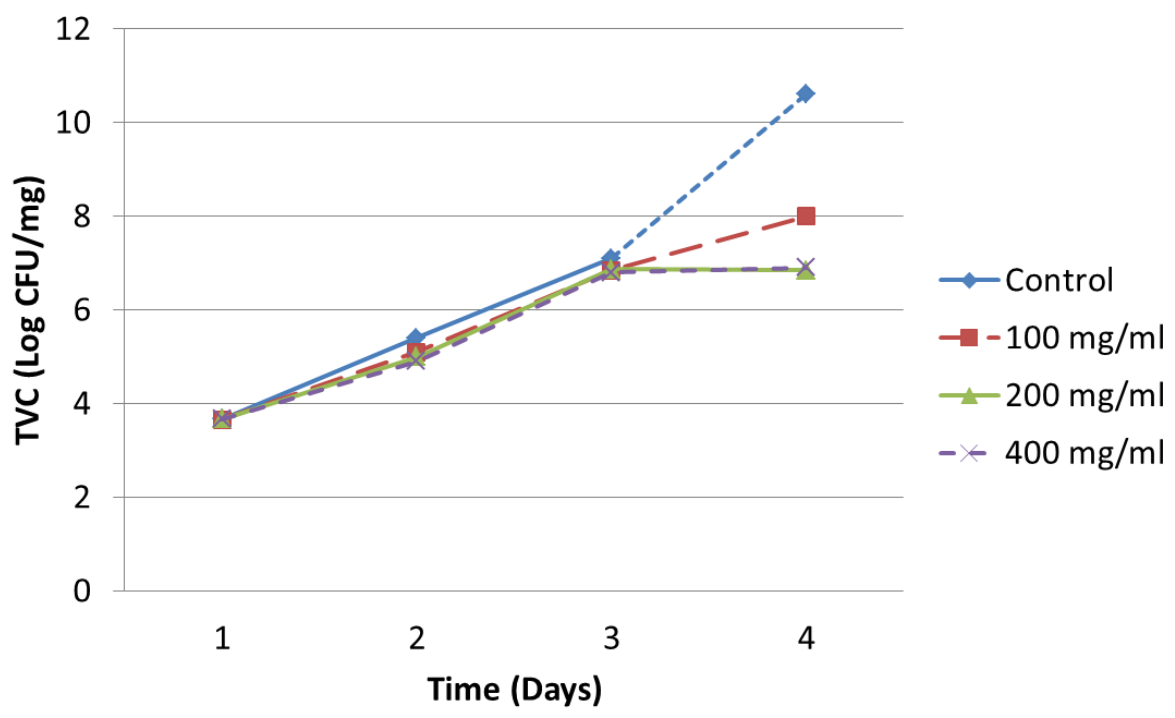

Figure 4. The total viable count of bacteria in ground beef meat stored at 4 degrees during a 10-day period with and without sumac extracts (Khalkhali, 2018)

\subsection{The Effect of Using Sumac Extracts on the Sensory Properties of Meat}

Although the addition of sumac extracts to meat can increase its shelf life by reducing the total microbial counts (Gabr, 2014), however spices in general could attribute to dramatic sensorial, organoleptic and physical changes to food, especially that some extracts require a higher minimum inhibitory level compared to those applied in vivo that could contribute to reduction in microbial counts in vitro i.e. in food (Gottardi, 2016). In poultry for example, treating broiler wings with Sumac extract has led to the formation of a pale color and an undesirable acidic odor (Gulmez, 2006). However, no studies have demonstrated the sensorial changes that could be caused by Sumac in red meat.

\subsection{The Safety of Rhus coriaria (Sumac) Extracts}

Rhus coriaria is known for its high content of Tannins that play the major role in reducing pathogenic bacteria in meat and rendering meat for safer consumption (Gabr, 2014). The U.S Food and Drug Administration (FDA) lists the Tannic acid on the adopted list of Generally Recognized as Safe (GRAS) food components (FDA, 2018). The administration also lists Rhus coriaria as a safe source of Tannic acid that can be extracted from the herb in many means, mentioning extraction by methanol as one of them (FDA, 2018).

\section{Conclusions}

Meat and meat products should not contain micro-organisms or their toxins or metabolites in quantities that present an unacceptable risk for human health. The safety of meat processed by industrial chain is mainly ensured by a preventive approach, such as implementation of good hygiene practice and application of procedures based on hazard analysis and critical control point (HACCP) principles. According to a survey conducted by the Ministry of Industry in 2007, the industrial sector is considered one of the most important contributors to the Lebanese Economy where it ensures the employment of the largest percentage of the industrial work force $(24.9 \%)$ and produces the largest share of industrial output (25.7\%). Moreover, this sector accounts for the largest portion of industrial added value $(26.9 \%)$ where its fixed assets are the largest of industrial sector at $13.9 \%$ of that sector's totals (El Tabch, 2018).

Therefore, it is critically important to put food safety as one of the priorities to improve and assure the continuity of the success of industrial sector in Lebanon. By enhancing the food safety system, the Lebanese food exports will be further certified, the population' strength will be promoted and thus, less health care cost will be managed. There is a warning need for a Lebanese law to be issued by the government particularly with the large corruption and lack of compliance with food safety schemes like HACCP and GHP. Worth to mention that, in small and local businesses, it was important to look for a natural, harmless alternative to render food safer. As previously proved, using herbal extracts to reduce foodborne pathogens is an effective strategy to increase the shelf life of many products, including red meat, and thus decreasing the burden of foodborne illness. Besides, the effect of Sumac extracts in meat has shown a promising tenderizing effect with antibacterial against pathogens that exceeds that of synthetic preservatives and antibiotics, this will lead to a reduced use of chemicals that may impose a risk for overall human health. Moreover, the use of Sumac extract may be considered as an effective step to be taken to improve the meat's safety. This strategy has been proved to be helpful 
as safe, economical, and scientifically proven mechanism to reduce pathogens in consumed food. Therefore, it is important to increase education and awareness among butcher shops and the meat industry sector to embrace Sumac extracts as the new approach to render meat a safer food. As the pace of technological change quickens, we need to be sure that the different sectors, including the industrial one, are up to date to recent studies and research needed to thrive with the Fourth Industrial Revolution and to keep up with technology as two weapons needed to become a competing country at the level of the world.

\section{REFERENCES}

[1] AbouReidah I, Jamous R, Shtayeh M. Phytochemistry, pharmacological properties and industrial applications of Rhus coriaria L. 2014. Jordan Journal of Biological Sciences. Nablus, Palestine.

[2] AlJaber G. Antibacterial effect of two phenolic extracts from Rhus coriaria. 2008. Basra Research Journal. Basra, Iraq.

[3] Alwan B. Effect of Rhus coriaria crude extract on inhibition and adhesion of pseudomonas aeruginosa and E. coli clinically isolated from patients infected with acute urinary tract inflammation. 2009. Primary Education College Journal.

[4] Ardalani H, Moghadam M, Hadipanah A, Fotovat F, Azizi A Soltani J. Identification and characterization of chemical composition of Rhus coriaria L. fruit from Hamadan western Iran. 2016. Journal of Herbal Drug. Hamedan. Iran.

[5] Asqc, American Scociety for Quality. The Quality Auditor's Haccp Handbook Hardcover. Asq P; 2001.

[6] Australian Institute of food safety. (2018). What are the different types of food contamination. Retrieved from: https://www.foodsafety.com.au/faq/what-are-the-differenttypes-of-food-contamination

[7] Bakhtiary F., Sayevand R., Remely M., Hippie B., Hosseini H., Haslberger A. (2015). Evaluation of bacterial contamination sources in meat production line. Journal of Food Quality

[8] Barros M., Nero L., Monteiro A., Beloti V. Identification of main contamination points by hygiene indicator microorganisms in beef processing plants. 2007. Food Sciences and Technology.

[9] Chakraborty A, Ferk F, Simić T, Brantner A, Dušinská M, Kundi M, Hoelzl C, Nersesyan A and Knasmüller S. 2009. DNA protective effects of Sumac h (Rhus coriaria L.), a common spice: Results of human and animal studies. Mutation Res/Fudamental and Molecular Mechanisms of Mutagenesis

[10] Dastjerdi E, Monadi E, Khalighi H, Torshabi M. Down-Regulation of Glycosyl Transferase Genes in Streptococcus Mutans by Punica Granatum L. Flower and Rhus Coriaria L. Fruit Water Extracts. 2015. Iranian Journal of Pharmaceutical Research. Tehran, Iran.
[11] Dave D, Ghaly A.E. Meat Spoilage Mechanisms and Preservation techniques. 2011. American Journal of Agriculture and biological sciences.

[12] El-Jardali F, Hammoud R, Kamleh, R., Jurdi, M. K2P Briefing Note: Protecting Consumers in Lebanon: The Need for Effective Food Safety System. Knowledge to Policy (K2P) Center. Beirut, Lebanon; November 2014

[13] World Health Organization \& Food and Agriculture Organization of the United Nations. (2016). Statistical aspects of microbiological criteria related to foods: a risk managers guide. World Health Organization.

[14] Food and Drug administration. (2018). CFR- Code of Federal regulations title 21. Retrieved from: https://www.a ccessdata.fda.gov/scripts/cdrh/cfdocs/cfcfr/CFRSearch.cfm ?fr $=184.1097$

[15] Gabr A., Metwally M., Al Ghadir A. Antioxidant and antibacterial constituents of Rhus coriaria. 2014.

[16] Gottardi D., Bukvicki D., Parsad S., Tyagi A. Beneficial Effects of Spices in food preservation and safety. Frontier microbiology. 2016. PubMed PIMD: 27708620.

[17] Gulmez M. The Effect of Water Extract of Sumac (Rhus coriaria L.) and Lactic Acid on Decontamination and Shelf Life of Raw Broiler Wings. 2006. Poultry Science. Kars, Turkey.

[18] Khalkhali F., Noveir M. Effect of Sumacc (Rhus coriaria) and rosemary (Rosmarinus officinalis) water extracts on microbial growth changes in ground beef meat. (2018). Journal of Food and bioprocess engineering.

[19] Lahr J. Beef Carcasses Microbial Contamination - Post Slaughter Number of Bacteria, Sources of Contamination and Variability of Data. 1996. American Meat Science Association.

[20] Liu K, Huang A, Wu P, Lin H, Chueh F, Yang J., Lu C C,Chiang J H, Meng M, Chung J G. 2011. Gallic acid suppresses the migration and invasion of $\mathrm{PC}-3$ human prostate cancer cells via inhibition of matrix metalloproteinase-2 and -9 signaling pathways. Oncology Reports, 26: 177-184.

[21] Marriott N. Essentials of Food Sanitation. 1st ed. Springe; 1997.

[22] National institute of Diabetes, Digestive, and Kidney Diseases. (2018). Foodborne illnesses. Retrieved from: https://www.niddk.nih.gov/health-information/digestive-di seases/foodborne-illnesses.

[23] Nollet L, Boylston T, Chen F, Coggins P, Gloria M, Hyldig G, Kerth Ch, McKee L, Hui Y. Handbook of Meat, Poultry and Seafood Quality. 1st ed. Wiley-Blackwell; 2007.

[24] Painter J., Hoekstra R., Ayers T., Tauxe R., Braden C., Angulo F., Griffin J. Attribution of foodborne illnesses hospitalizations and deaths to food commodities by using outbreak data 1998-2009. 2013. Center for Disease Control and Prevention (CDC)

[25] Rani Z., Hugo A., Hugo C., Vimiso P., Muchenje V. (2015). The effect of post slaughter handling during distribution on microbiological quality and safety of meat in the formal and informal sectors of South Africa, a review. Journal of 


\section{Animal Sciences}

[26] Rather A., Yin Koh W., Pack W., Lim J. (2017). The Sources of chemical contaminants in food and their health implications. Frontier pharmacology. PubMed PIMD: 29204118.

[27] Sakhr Khawla, El Khatib Sami, The Use of Rhus coriaria (Syrian Sumac) as a Meat Tenderizer. Its Effect on Fat, Protein and Collagen Profiles on Pectoralis superficialis Cut. Turkish Journal of Agriculture - Food Science and Technology; Vol 7, No 8 (2019).

[28] Shabir A. Rhus coriaria Linn, a plant of medicinal, nutritional and industrial importance: a review. 2012. The journal of animal and plant sciences.

[29] Shidfara F, Hosseinic S. The Effect of Sumac Rhuscoriaria L. Powder on Serum Glycemic Status, ApoB, ApoA-I and Total Antioxidant Capacity in Type 2 Diabetic Patients. 2014. Iranian Journal of Pharmaceutical Research.

[30] Tabch L., (2018). The Food and Beverages Sector: Position, Problems and Prospects. Retrieved from:https://www.ccib. org.lb/uploads/5b447b6d402a6.pdf

[31] United Nations Industrial Development Organization UNIDO. (2009). Qualitative Biological Risk Assessment of meat sector in Lebanon- an output of the project: Assistance to the Lebanese meat and milk processing sector in their efforts to gain increased market access. Retrieved from: https://open.unido.org

[32] University of Nebraska-Lincoln. Institute of Agriculture and Natural Resources. (2019). Retrieved from:https://food.unl .edu/chemical-hazards

[33] World health organization (WHO). (2015). From Kebabs to Fattoush-keeping Lebanon's Food safe. Retrieved from: https://www.who.int/features/2015/lebanon-food-safety/en /

[34] World health organization (WHO). (2019). Food Safety. Retrieved from: https://www.who.int/news-room/fact-shee ts/detail/food-safety

[35] World Health Organization WHO. WHO Global strategy for food safety: safer food for better health. Retrieved from: www.WHOint/fsf

[36] The Actual Life of Sumac. (2013) Wallace Extract on Bacteria Causing Soft Rot on Potatoes. Journal of Babylon University 